\title{
CORRESPONDENCE
}

Evolutionary theory: it's on the school syllabus in Mexico

SIR - As Andrew Moore writes in his Commentary 'Science teaching must evolve' (Nature 453, 31-32; 2008), online resources may help to improve the teaching of evolutionary theory in European secondary schools. A broader comparison with other countries is warranted.

In Mexico, there is no

creationist movement and the teaching of evolution is encouraged. The Universidad Nacional Autónoma de México has developed high-school programmes based around sequence comparison and phylogenetic reconstruction techniques, as well as the origin of life, early cell evolution and evo-devo issues. There are good reasons for this. First, as every practising scientist knows, understanding evolutionary processes is enriched by an eclectic attitude towards traditional palaeontology and comparative anatomy. Second, an evolutionary perspective is valuable as a teaching tool that provides a unifying framework for bringing together apparently disparate fields from the life sciences.

It is difficult to accept Moore's implication that the origin of life has no place in the evolution syllabus. If not there, where? There are risks in leaving this issue unattended, as shown by the infamous 2004 statement by Dover High School in Pennsylvania that "Intelligent Design is an explanation of the origin of life that differs from Darwin's view ... The school leaves the discussion of Origins of Life to individual students and their families."

Equally disturbing is Moore's questioning of the scientific maturity of origin-of-life studies, which he describes as "far from sound evolutionary theory". How life appeared is not known, but a better understanding of the prebiotic environment and the

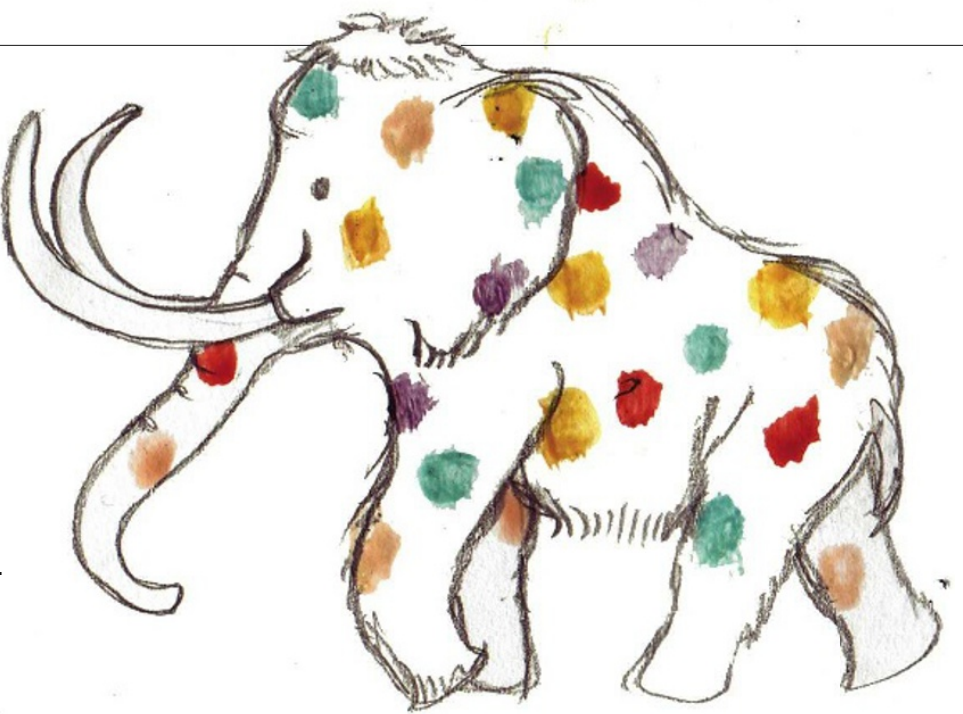

recognition of the RNA world as an early evolutionary stage have provided important insights. As molecular phylogeny cannot be extended to an evolutionary period before the emergence of ribosome-mediated protein biosynthesis, it cannot provide direct information about the first living systems.

The inclusion of evolutionary theory in school curricula should teach students how to find the right answers and how to pose the proper questions.

Antonio Lazcano, Arturo Becerra Facultad de Ciencias, UNAM, Ap. Postal 70-407, Cd. Universitaria, 04510 Mexico, D.F., México Juli Peretó Institut Cavanilles de Biodiversitat i Biologia Evolutiva, Universitat de València, Ap. Postal 22085, E-46071, València, Spain

\section{Evolutionary theory: don't skimp on teaching its history}

SIR — In his Commentary 'Science teaching must evolve' (Nature 453, 31-32; 2008), Andrew Moore criticizes the absence of the past four decades' efforts in genesequencing technology and bioinformatics from European secondary-school curricula. He notes that "phylogeny based on similarity of form is fundamentally unsound because of the adaptation and convergent evolution witnessed in nature". There is self-evident truth in this, but molecular phylogenetics is also based on similarity of form, albeit DNA's. Many of the computer programs used to seek out molecular relationships among organisms are used to determine morphological relationships thereby revealing those many instances of convergence.

Data are data, whether they be molecular or morphological. If students are short-changed when it comes to the teaching of evolution, it is in its history, which is highly relevant today.

David M. Williams Department of Botany, the Natural History Museum, Cromwell Road, London SW7 5BD, UK Malte C. Ebach International Institute for Species Exploration, School of Life Sciences, Arizona State University, PO Box 874501, Tempe, Arizona 852874501, USA

\section{Learning to navigate the geography of citation indexes}

SIR — In his Correspondence

'Hall and Keynes join Arbor in the citation indexes' (Nature 452, 282; 2008), Daniel Postellon describes the distinguished careers of Milton Keynes, Walton Hall and Ann Arbor. In the last case, I note that Professor Arbor has an h-index of 1 from the Web of Science database provided by Thomson Scientific's ISI Web of Knowledge. This is based on her five citations for the year 2007: two articles, two letters and one abstract.

An author search in the Web of Science reveals that Chevy Chase (not to be confused with Chevy Chase, Maryland) has co-authored a letter with Howard Kaplan (H. Kaplan Am. Sci. 96, 3; 2008). My own institution, Wilfrid Laurier University, is also an author (S. Cadell et al. J. Palliat. Care 23, 273-279; 2007).

Irrespective of how these errors are created, the rising use of systems in which citation information moves directly from the search of a database or citation index to a bibliographic management system, and then into a reference list, means that inexperienced students and researchers who are not savvy enough to detect these errors will propagate them further.

Vigilance is required by all users of citation indexes and databases.

Debbie Chaves Wilfrid Laurier University, 75 University Avenue West, Waterloo, Ontario N2L 3C5, Canada

\section{Vaccine failure is not a 'crisis' for HIV research}

SIR - In your Editorial 'Broken promises' (Nature 452, 503; 2008), you say: “Decisions to move Merck's vaccine candidate and a previous failed candidate into clinical trials were based only partly on science." I would like to clarify the position on the Merck vaccine trial, as there is no evidence to support this assertion.

The scientific consensus was that the phase Ilb efficacy trial of this vaccine candidate was justified. Inducing CD8 T-cell responses in the majority of vaccine recipients by strategies other than live attenuated vaccines has proved extremely difficult, and the adenovirus serotype- 5 platform was the first to overcome the problem.

The trial was designed to be smaller than a traditional phase III and included an interim analysis after the first 30 infections to 